\title{
Atividades antioxidante e alelopática de extratos foliares obtidos de Eugenia dysenterica
}

\author{
Antioxidant and allelopathic activities of leaf extracts of Eugenia dysenterica \\ Rafael Pozzi Malheiros, Ana Maria Mapeli e Luciana Lucas Machado \\ Universidade Federal do Oeste da Bahia, campus Barreiras - BA, Brasil \\ rafaelpozzi@hotmail.com; anammapeli@gmail.com; luclucamachado@gmail.com
}

\begin{abstract}
Resumo
O objetivo deste trabalho foi avaliar o potencial antioxidante e alelopático dos extratos etanólico e hidroalcoólicos 70:30 e 50:50 (etanol:água) obtidos das folhas de Eugenia dysenterica. A atividade antioxidante dos e extratos foi avaliada por meio do método de sequestro de radicais livres usando 2,2-difenil-1-picril-hidrazila (DPPH). A avaliação da atividade alelopática foi realizada em condições de laboratório, considerando-se a porcentagem de germinação, índice de velocidade de germinação, comprimento da radícula/raiz primária e comprimento do hipocótilo/coleóptilo de sementes de alface e milho. Os resultados obtidos foram submetidos à análise de variância e as médias comparadas pelo teste Scott Knott ao nível de 5\% de probabilidade. Em relação ao potencial antioxidante, todos os extratos demonstraram atividade, com valores de concentração inibitória (IC50) de 0,73; 1,68 e 1,83mg/mL para os extratos etanólico, hidroalcoólico 70:30 e hidroalcoólico 50:50, respectivamente. Quanto a atividade alelopática, os extratos etanólico e hidroalcoólico 70:30 e 50:50 reduziram o índice de velocidade de germinação de alface e inibiram o crescimento médio da radícula/raiz primária e hipocótilo/coleóptilo das espécies alvo. Portanto, os extratos testados de E. dysenterica apresentam potencial antioxidante e efeito alelopático inibitório sobre o desenvolvimento inicial de alface e milho.
\end{abstract}

Palavras-chave: Cagaita, radicais livres, alface, milho, inibição.

\begin{abstract}
The aim of this study was to evaluate the antioxidant and allelopathic potential of ethanolic and hydroalcoholic 70:30 and 50:50 (ethanol: water) extracts from the leaves of Eugenia dysenterica. The antioxidant activity of the extracts were evaluated by applying the free radical scavenging method using the 2,2-diphenyl-1-picrylhydrazyl radical (DPPH). The allelopathic bioassays were carried out in laboratory, considering germination percentage, Index of Germination Speed (IVG), radicle / primary root length and hypocotyl / coleoptile length of lettuce and corn seeds. All parameters underwent variance analysis, and the mean values were compared by means of Scott-Knott test ( $p \leq$ 0.05). In relation to the antioxidant potential all extracts showed activity, with inhibitory concentration (IC50) at $0.73 ; 1.68$ e $1.83 \mathrm{mg} / \mathrm{mL}$ for the ethanolic, hydroalcoholic 70:30 e hydroalcoholic 50:50, respectively. Regarding allelopathic activity, all extracts reduced the IVG of lettuce and inhibit the radicle / primary root growth and hypocotyl / coleoptile of target species. Therefore, the extracts tested of E. dysenterica showed antioxidant potential and allelopathic inhibitory effect on the initial development of lettuce and corn.
\end{abstract}

Keywords: Cagaita, free radicals, lettuce, corn, inhibition. 


\section{Introdução}

O cerrado, dentro da biodiversidade brasileira, é uma potencial fonte de espécies vegetais que desempenha importante papel na produção de compostos bioativos (RODRIGUES e CARVALHO, 2007). Estes compostos são originados do metabolismo secundário e estão diretamente envolvidos nos mecanismos que permitem a adequação da planta ao seu meio, além de apresentarem diversas atividades biológicas (MIRANDA, 2010).

Neste bioma, destaca-se a família Myrtaceae, a qual é uma das mais numerosas da flora brasileira, composta por 23 gêneros e 1000 espécies, distribuídas em vários estados do Brasil (ROMAGNOLO e SOUZA, 2006). O gênero Eugenia é considerado um dos maiores desta família, com aproximadamente 500 espécies de árvores e arbustos (OLIVEIRA et al., 2005). Estudos fitoquímicos realizados com espécies deste gênero revelaram a presença de flavonóides, taninos e terpenos (FRIGHETTO et al., 2005; OLIVEIRA et al., 2005), o que pode estar associado às atividades anti-inflamatória, analgésica, antimicrobiana e antioxidante desenvolvidas por representantes de Eugenia (FALCÃO et al., 2005; LIMA et al., 2002).

Entre as espécies importantes deste gênero, destaque-se Eugenia dysenterica D.C., popularmente conhecida como cagaita, a qual é uma árvore frutífera nativa do Cerrado, bastante aproveitada pela população local como fonte de alimentação e para fins medicinais (BEZERRA et al., 2002). Esta espécie é descrita como potencial produtora de compostos secundários ativos, incluindo as substâncias fenólicas (PEREIRA et al., 2012), que têm recebido bastante atenção, sobretudo por apresentarem comprovado potencial antioxidante e alelopático (SOUZA et al., 2007). Entretanto, a produção de metabólitos secundários varia quantitativa e qualitativamente de acordo com as condições ambientais. Neste contexto, são escassos os trabalhos sobre o potencial antioxidante e alelopático de E. dysenterica presente no Cerrado do Oeste Baiano.

A avaliação da atividade antioxidante tem sido uma questão importante devido à relevância para a saúde humana, uma vez que a utilização de plantas na forma de sucos ou chás, como fontes de agentes antioxidantes naturais, pode auxiliar no tratamento de várias doenças como aterosclerose, doenças cardíacas, do sistema nervoso central, entre outras (SILVA et al., 2005).

Outra atividade importante corresponde a alelopatia, que pode ser definida como a capacidade que as plantas possuem de interferir no desenvolvimento de outras plantas, de forma positiva ou negativa, por meio de substâncias químicas liberadas na atmosfera ou no solo (FERREIRA, 2004). Em função dessas alterações, a alelopatia é reconhecida como um processo ecológico importante em ecossistemas naturais e manejados, influenciando a sucessão vegetal primária e secundária, estrutura, composição e dinâmica de comunidades vegetais nativas ou cultivadas (WANDSCHEER e PASTORINI, 2008).

Portanto, o objetivo do presente trabalho foi avaliar as atividades antioxidante e alelopática de diferentes extratos foliares (etanólico, hidroalcoólico 70:30 e 50:50) obtidos de E. dysenterica presente no Oeste da Bahia.

\section{Material e métodos}

\subsection{Coleta do material}

A coleta do material vegetal de $E$. dysenterica foi realizada na Serra da Bandeira $\left(-12^{\circ} 04^{\prime} 48^{\prime} \mathrm{S}\right.$ e $\left.-45^{\circ} 00^{\prime} 36^{\prime \prime} \mathrm{W}\right)$, localizada no município de Barreiras - BA. A coleta ocorreu no período da manhã no final do mês de agosto de 2013. Os materiais botânicos testemunhos foram coletados e comparados com a exsicata de número de registro 002362 depositada no Herbário da Universidade Federal do Oeste da BahiaBRBA/UFOB.

\subsection{Preparação dos extratos}

Para a preparação do extrato etanólico, as folhas foram secas à temperatura ambiente, trituradas e imersas em etanol $92 \%$, por 48 horas. Após este procedimento, realizou-se filtragem, descartando-se os materiais sólidos e removendo-se o solvente em evaporador rotativo à temperatura de aproximadamente $70^{\circ} \mathrm{C}$, até obter-se um produto de consistência pastosa. A preparação dos extratos hidroalcoólicos seguiu o mesmo procedimento do etanólico, sendo utilizadas as seguintes proporções: 70:30 (etanol: 
água destilada) e 50:50 (etanol: água destilada). Entretanto, após remoção do etanol, o material foi filtrado, congelado e liofilizado a $-35^{\circ} \mathrm{C}$.

\subsection{Determinação da atividade antioxidante de extratos de E. dysenterica}

A atividade antioxidante das amostras foi estudada frente à capacidade de sequestro do radical 2,2-difenil-1-picril-hidrazila (DPPH), conforme o método descrito por Mensor et al. (2001). Assim, 0,001g de extrato etanólico e hidroalcoólicos de folhas de E. dysenterica foram dissolvidos em $10 \mathrm{~mL}$ de metanol e testados em cinco concentrações: 0,0001; 0,001; 0,01; 0,1 e $1,0 \mathrm{mg} / \mathrm{mL}$. Soluções idênticas foram preparadas acrescidas de 1,2mg de DPPH, dissolvido em $100 \mathrm{~mL}$ de metanol e mantidas no escuro, por 30 minutos, à temperatura ambiente. Em seguida, foram realizadas leituras de absorvância das amostras, no comprimento de onda de 520nm, em espectrofotômetro. A porcentagem de inibição foi obtida por meio da absorção da solução contendo amostra em relação a uma solução controle de DPPH sem amostra, a partir da seguinte fórmula: Porcentagem de inibição = (1 - Abs. da amostra/Abs. do DPPH) x 100.

Após o cálculo, foi construído um gráfico de porcentagem de inibição versus a concentração. Para o cálculo da concentração inibitória ( $\mathrm{IC}_{50}$ ) foi utilizada a equação da reta, substituindo o valor de y por 50 para obtenção da concentração da amostra com capacidade de reduzir 50\% do DPPH. Como parâmetro de comparação foi empregado vitamina C (Ácido ascórbico), nas mesmas condições dos ensaios.

\subsection{Determinação da atividade alelopática de extratos de E. dysenterica}

Nos bioensaios, foram utilizadas cinco concentrações: 250, 500, 1000, 2000 e 4000mg/L, sendo a última representada pela solução estoque e as demais obtidas por diluições. Os efeitos dos extratos foram comparados à testemunha (água destilada).

As sementes foram adquiridas em estabelecimento comercial e selecionadas quanto à uniformidade de tamanho, formato e coloração. Após, realizou-se a desinfestação fúngica, a partir da imersão em hipoclorito de sódio a 2\% (BRASIL, 2009).
Nos bioensaios com alface, discos de papel filtro, contidos em placas de Petri $(9 \mathrm{~cm}$ de diâmetro), foram impregnados com $2 \mathrm{~mL}$ das concentrações dos extratos. Após a evaporação do solvente, foram adicionadas $2 \mathrm{~mL}$ de água destilada e, em seguida, foram semeadas, aleatoriamente, sobre cada disco de papel filtro, 50 sementes. Nos bioensaios com milho, procedimento similar foi realizado, entretanto, os discos de papel filtro contidos em placas de Petri ( $15 \mathrm{~cm}$ de diâmetro) foram umedecidos com $5 \mathrm{~mL}$ das soluções testes e, após evaporação do solvente, foram adicionados $5 \mathrm{~mL}$ de água destilada, sendo posteriormente semeadas 25 sementes. As placas de Petri foram mantidas em fotoperíodo constante, a temperatura de $25^{\circ} \mathrm{C}$, em ambiente climatizado (BRASIL, 2009).

A porcentagem de germinação foi determinada diariamente, considerando a protusão radicular de $2 \mathrm{~mm}$. $\mathrm{O}$ experimento foi concluído quando a germinação foi nula por três dias consecutivos. Os valores de porcentagem de germinação foram transformados em:

$$
\operatorname{arcsen}\left(\sqrt{\frac{x}{100}}\right)
$$

A porcentagem de plântulas germinadas foi calculada segundo metodologia descrita por Labouriau (1983) e o índice de velocidade de germinação (IVG) segundo Maguire (1962):

$$
\mathrm{IVG}=\frac{\mathrm{G} 1}{\mathrm{~N} 1}+\frac{\mathrm{G} 2}{\mathrm{~N} 2}+\ldots+\frac{\mathrm{GN}}{\mathrm{NN}}
$$

Em que: G1, G2 e GN representam o número de sementes normais germinadas até o enésimo dia. $\mathrm{N} 1, \mathrm{~N} 2$ e NN representam o número de dias em que se avaliou a germinação G1, G2 e GN.

O comprimento da radícula/raiz primária e hipocótilo/coleóptilo foram medidos três dias após a protusão radicular, utilizando-se papel milimetrado.

O delineamento utilizado foi inteiramente casualizado, em esquema fatorial 3x6 (extrato $\mathrm{x}$ concentração), quatro repetições, sendo a unidade experimental constituída de 25 ou 50 diásporos, dependendo da espécie alvo, 10 plântulas para o crescimento da radícula/raiz primária e do hipocótilo/coleóptilo. 


\subsection{Análise estatística}

Os resultados obtidos foram submetidos à análise de variância (ANOVA), sendo as médias comparadas pelo teste Scott Knott ao nível de 5\% de probabilidade, utilizando o programa para análises estatísticas Assistat 7.7 beta (SILVA e AZEVEDO, 2002).

\section{Resultados e discussão}

\subsection{Determinação da atividade antioxidante}

Analisando os resultados, observou-se que o extrato etanólico das folhas apresentou a maior capacidade de captação de radicais livres, com IC 50 de $0,73 \mathrm{mg} / \mathrm{mL}$, cerca de $67,6 \%$ menor em comparação ao padrão que apresentou $\mathrm{IC}_{50} \mathrm{de}$ $2,25 \mathrm{mg} / \mathrm{mL}$, demonstrando um alto potencial antioxidante para esse tipo de extrato (Tabela 1). Estes resultados sugerem a presença de maior quantidade de compostos fenólicos no extrato etanólico, o que pode ter favorecido a maior atividade antioxidante.

Os extratos hidroalcoólicos também apresentaram atividade antioxidante significativamente diferente da vitamina $\mathrm{C}$, com valores médio de $\mathrm{IC}_{50}$ de $1,75 \mathrm{mg} / \mathrm{mL}$, cerca de 25,3\% menor em relação ao padrão ( Tabela 1).

Tabela 1 - Valores de IC 50 obtidos nos ensaios de atividade antioxidante dos extratos de $E$. dysenterica pelo método do DPPH

\begin{tabular}{cc}
\hline AMOSTRAS & $\mathrm{IC}_{50} \mathrm{mg} / \mathrm{mL}$ \\
\hline Vitamina C & $2,25 \mathrm{a}$ \\
Extrato etanólico & $0,73 \mathrm{c}$ \\
Extrato hidroalcoólicos 70:30 & $1,68 \mathrm{~b}$ \\
Extrato hidroalcoólicos 50:50 & $1,83 \mathrm{~b}$ \\
\hline
\end{tabular}

Médias seguidas pela mesma letra não diferem estatisticamente entre si pelo teste Scott - Knott ao nível de 0,05 de probabilidade. $\mathrm{IC}_{50}=$ concentração da amostra que reduz 50\% da concentração inicial de DPPH.

Estudos realizados por Magina (2008) sobre atividade antioxidante dos extratos etanólicos foliares de E. brasiliensis, E. beaurepaireana e E. umbelliflora demonstraram valores de IC 50 de 27,6, 18 e $39,7 \mathrm{mg} / \mathrm{mL}$, respectivamente, resultados de potencial antioxidante inferiores aos obtidos no presente estudo. O extrato etanólico foliar de $E$. uniflora também apresentou valor alto de IC 50 $(185,47 \mathrm{mg} / \mathrm{mL})$ (SOBRAL-SOUZA et al., 2014). Desta forma, os dados verificados neste trabalho demonstraram que os extratos foliares de $E$. dysenterica apresentam maior atividade antioxidante em relação a outras espécies do mesmo gênero.

Estudos fitoquímicos realizados com espécies de Eugenia sp. revelaram a presença de flavonóides, taninos e terpenos (OLIVEIRA et al., 2005), o que pode estar associado às atividades anti-inflamatória, analgésica, antimicrobiana e, principalmente, antioxidante observada nesta espécie (FALCÃO et al., 2005). Nesse sentido, a avaliação desta atividade tem sido uma questão importante devido à relevância para a saúde humana, uma vez que a utilização de plantas na forma de sucos ou chás, como fontes de agentes antioxidantes naturais, pode auxiliar no tratamento de várias doenças como aterosclerose, doenças cardíacas, do sistema nervoso central, entre outras (SILVA et al., 2005).

\subsection{Determinação da atividade alelopática}

Em relação à porcentagem de germinação e o índice de velocidade de germinação, não houve diferença significância para a interação Extrato $x$ Concentração. Todos os extratos tiveram um efeito semelhante, não detectando-se diferença estatística entre eles (Tabela 2).

Tabela 2 - Efeito de diferentes extratos da folha de $E$. dysenterica sobre a percentagem de germinação (G\%) e índice de velocidade de germinação (IVG) de alface

\begin{tabular}{ccc}
\multicolumn{4}{c}{ germinação (IVG) de alface } \\
\hline TRATAMENTO & G\% & IVG \\
\hline Etanólico & $1,45 \mathrm{~A}$ & $48,16 \mathrm{~A}$ \\
Hidroalcoólico 70:30 & $1,44 \mathrm{~A}$ & $47,88 \mathrm{~A}$ \\
Hidroalcoólico 50:50 & $1,45 \mathrm{~A}$ & $48,04 \mathrm{~A}$ \\
\hline
\end{tabular}

Médias seguidas pela mesma letra, na coluna, não diferem entre si pelo teste de Scott - Knott $(p \leq 0,05)$.

Em relação às concentrações utilizadas na avaliação destes mesmos parâmetros, não ocorreu diferenças significativas na porcentagem de germinação. Já para o índice de velocidade de germinação, a concentração $4000 \mathrm{mg} / \mathrm{L}$ foi a única que promoveu efeito significativo, causando uma redução média de $4,15 \%$ em relação à testemunha (Tabela 3). Segundo Ferreira e Áquila (2000) a interferência alelopática é mais incidente sobre o crescimento das plântulas do que sobre o fenômeno da germinação, devido ao fato deste processo ser menos sensível à ação dos 
aleloquímicos. Embora a porcentagem de germinação possa não ser significativamente afetada pela ação de aleloquímicos, o padrão de germinação pode ser modificado, verificando-se diferenças na velocidade da germinação de sementes submetidas a tais compostos (SANTANA et al., 2006).

Tabela 3 - Efeito das diferentes concentrações de extratos da folha de E. dysenterica sobre a percentagem de germinação (G\%) índice de velocidade de germinação (IVG) de alface

\begin{tabular}{ccc}
\hline CONCENTRAÇÃO & G\% & IVG \\
\hline $0 \mathrm{mg} / \mathrm{L}$ & $1,48 \mathrm{~A}$ & $48,63 \mathrm{~A}$ \\
$250 \mathrm{mg} / \mathrm{L}$ & $1,46 \mathrm{~A}$ & $48,39 \mathrm{~A}$ \\
$500 \mathrm{mg} / \mathrm{L}$ & $1,45 \mathrm{~A}$ & $47,53 \mathrm{~A}$ \\
$1000 \mathrm{mg} / \mathrm{L}$ & $1,46 \mathrm{~A}$ & $48,53 \mathrm{~A}$ \\
$2000 \mathrm{mg} / \mathrm{L}$ & $1,45 \mathrm{~A}$ & $48,01 \mathrm{~A}$ \\
$4000 \mathrm{mg} / \mathrm{L}$ & $1,35 \mathrm{~A}$ & $46,36 \mathrm{~B}$ \\
\hline
\end{tabular}

Médias seguidas da mesma letra, na coluna, não diferem entre si pelo teste de Scott - Knott $(p \leq 0,05)$.

Teixeira et al. (2004), utilizando extrato aquoso de Stilozobium aterrimum Piper \& Tracy (mucuna-preta), também não observaram efeitos na porcentagem de germinação de sementes de alface, porém o índice de velocidade de germinação foi mais afetado em comparação aos resultados aqui obtidos, promovendo uma redução média de $81 \%$.

Em relação ao crescimento da radícula e hipocótilo de sementes de alface, observou-se interação significativa entre o tipo de extrato e a concentração testada. A respeito do crescimento da radícula, o extrato etanólico promoveu efeitos inibitórios menores em relação aos hidroalcoólicos, exceto na sua maior concentração (4000mg/L) (Tabela 4).

Este fato pode sugerir que, durante o preparo do extrato, a mistura etanol e água pode facilitar a extração de substâncias inibidoras especificas presentes nas folhas ou possibilitar a extração em maiores quantidades. De maneira geral, todos os extratos inibiram o crescimento da radícula de alface, sendo observado um aumento significativo na inibição à medida que se aumenta a concentração nos casos do extrato etanólico e hidroalcoólico 50:50. Entretanto, o efeito do extrato etanólico só começou a ser observado a partir da concentração de $1000 \mathrm{mg} / \mathrm{L}$; enquanto nos extratos hidroalcoólicos a partir da menor concentração $(250 \mathrm{mg} / \mathrm{L})$ já foi possível verificar efeitos inibitórios significativos, confirmando a indicação de que nas condições testadas, mesmo em proporções menores, a água possibilitou a extração em maiores quantidades de substâncias inibidoras. Os extratos etanólico e hidroalcoólico 70:30 e 50:50 em suas maiores concentrações $(4000 \mathrm{mg} / \mathrm{L})$ promoveram uma inibição média de $71 \%$, $82 \%, 79 \%$, respectivamente, em relação à testemunha (Tabela 4), sugerindo que a espécie em questão apresenta potencial alelopático, e que os extratores utilizados foram eficientes na extração destas substâncias com atividade inibitória. $\mathrm{O}$ potencial alelopático verificado em $E$. dysenterica pode ser uma estratégia para retardar $\mathrm{o}$ estabelecimento de espécies herbáceas invasoras na sua proximidade e, com isso, diminuir os danos causados pela competição de recursos (GIOTTO et al., 2007).

Hüller e Schock (2011), ao testarem extrato aquoso de E. involucatra (cerejeira-do-mato), também observaram inibição $(42,6 \%)$ no crescimento radicular de alface. No entanto, este efeito foi menor em comparação aos promovidos pelos extratos de E. dysenterica. Dados semelhantes foram observados por Araújo et al. (2013), que verificaram redução no crescimento radicular de alface em, aproximadamente, $25 \%$, utilizando extrato etanólico da parte área de Rosmarinus officinalis L. (alecrim). Segundo Souza Filho et al. (1997) o alongamento da radícula é o indicador mais sensível aos efeitos dos extratos e, por isso, deve ser sempre considerado como um parâmetro alelopático.

Em relação ao crescimento do hipocótilo de alface, o extrato etanólico inibiu o crescimento apenas na concentração de $4000 \mathrm{mg} / \mathrm{L}$, promovendo uma inibição média de $34 \%$ em relação às testemunhas. Já os demais extratos tiveram efeitos inibitórios em menores concentrações, havendo proporcionalidade entre efeito e concentração (Tabela 5). 
Tabela 4 - Efeito da interação entre concentração e extrato de E. dysenterica sobre o crescimento da radícula $(\mathrm{cm})$ de alface

\begin{tabular}{ccccccc}
\hline EXTRATO & \multicolumn{6}{c}{ CONCENTRAÇÃO (mg/L) } \\
\hline Etanólico & 0 & 250 & 500 & 1000 & 2000 & 4000 \\
Hidroalcoólico 70:30 & $2,07 \mathrm{aA}$ & $2,99 \mathrm{aA}$ & $2,41 \mathrm{aA}$ & $1,62 \mathrm{aB}$ & $1,06 \mathrm{aC}$ & $0,60 \mathrm{aD}$ \\
Hidroalcoólico 50:50 & $2,07 \mathrm{aA}$ & $1,05 \mathrm{bB}$ & $0,77 \mathrm{bB}$ & $0,47 \mathrm{bB}$ & $0,42 \mathrm{bB}$ & $0,36 \mathrm{aB}$ \\
\hline
\end{tabular}

Médias seguidas pela mesma letra, minúscula na coluna e maiúscula na linha, não diferem significativamente entre si pelo teste de Scott-Knott a 5\% de probabilidade

Tabela 5 - Efeito da interação entre concentração e extrato de E. dysenterica sobre o crescimento do hipocótilo $(\mathrm{cm})$ de alface

\begin{tabular}{ccccccc}
\hline EXTRATO & \multicolumn{5}{c}{ CONCENTRAÇÃO (mg/L) } \\
\hline Etanólico & 0 & 250 & 500 & 1000 & 2000 & 4000 \\
Hidroalcoólico 70:30 & $1,34 \mathrm{aA}$ & $1,53 \mathrm{aA}$ & $1,52 \mathrm{aA}$ & $1,32 \mathrm{aA}$ & $1,33 \mathrm{aA}$ & $0,93 \mathrm{aB}$ \\
Hidroalcoólico 50:50 & $1,34 \mathrm{aA}$ & $1,39 \mathrm{bB}$ & $1,26 \mathrm{bB}$ & $0,97 \mathrm{bC}$ & $0,81 \mathrm{bC}$ & $0,56 \mathrm{bD}$ \\
\hline
\end{tabular}

Médias seguidas pela mesma letra, minúscula na coluna e maiúscula na linha, não diferem significativamente entre si pelo teste de Scott-Knott a 5\% de probabilidade

Dados semelhantes foram observados por Lima et al. (2011), utilizando extrato etanólico da parte área de Bidens pilosa Linné (picão-preto), pois constataram redução de $60,6 \%$ no hipocótilo de alface. Por outro lado, estudos com plântulas de Cucumis sativus L. (pepino) relataram estímulo no crescimento do hipocótilo quando estas foram submetidas ao extrato hidroalcoólico de Stryphnodendron adstringens Benth (barbatimão de folha miúda) (SALGADO et al., 2013). Estes resultados indicam que nem todos os aleloquímicos liberados pelas plantas possuem características inibitórias e podem, ao contrário, estimular o crescimento (LINHARES-NETO et al., 2014; MALHEIROS, et al., 2014).

De acordo com estes mesmos autores, diferentes respostas fisiológicas originadas em extratos hidroalcoólicos de um mesmo órgão vegetal são reflexo da diferença da concentração dos metabólitos secundários extraídos, uma vez que existe uma pequena diferença de polaridade nos solventes utilizados para o preparo dos extratos. Neste caso, as diferenças nos parâmetros fisiológicos até aqui observadas, promovidos não só pelos extratos hidroalcoólico, mas como também extrato etanólico, podem ser justificadas pelo fato dos mecanismos de extração de metabólitos secundários serem diferenciados devido à polaridade dos solventes utilizados também serem diferentes.

Nos bioensaios de germinação com milho, foram avaliados a porcentagem de germinação, índice de velocidade de germinação, crescimento da raiz primária e crescimento do coleóptilo. $\mathrm{Na}$ avaliação destes parâmetros não houve diferença significância para a interação Extrato $\mathrm{x}$ Concentração.

O extrato hidroalcoólico 70:30 promoveu um efeito inibitório na porcentagem de germinação quando comparado aos extratos etanólico e hidroalcoólico 50:50. Já no índice de velocidade de germinação, o extrato hidroalcoólico 50:50 apresentou menor inibição em comparação aos demais extratos. Em relação ao crescimento médio da raiz primária e coleóptilo do milho todos os extratos tiveram efeitos semelhantes (Tabela 6). Estes resultados podem sugerir que o extrato hidroalcoólico 70:30 foi mais efetivo na extração de compostos fenólicos em relação aos demais extratos. Solventes com alta polaridade, como a água, e solventes com polaridade muito baixas, ou apolares, não são bons extratores, por outro lado, a água em combinação com outros solventes orgânicos contribui para criar um meio moderadamente polar, o que favorece a extração de fenóis (LAPORNIK et al., 2005). Em extratos foliares de E. dysenterica podem ser encontrados teores elevados de flavonóides, compostos fenólicos simples, taninos, dentre outras substâncias fenólicas (BARA et al., 2009). Dessa forma, dependendo da polaridade do solvente utilizado, pode ocorrer uma maior ou menor extração destas classes de substâncias, o que 
pode influenciar no efeito promovido na germinação e crescimento de plântulas.

A respeito das concentrações utilizadas na avaliação dos parâmetros descritos acima, apenas as concentrações 2000 e $4000 \mathrm{mg} / \mathrm{L}$, independente do extrato, inibiram o crescimento da raiz primária e coleóptilo de plântulas de milho. Os outros parâmetros não tiveram diferença estatística entre as testemunhas e demais concentrações dos extratos. A maior concentração dos extratos proporcionou uma inibição média na raiz primária e coleóptilo de $40 \%$ e $27 \%$, respectivamente, em relação à testemunha (Tabela 7).

Tabela 6 - Efeito de diferentes extratos da folha de E. dysenterica sobre a percentagem de germinação (G\%) índice de velocidade de germinação (IVG) crescimento da raiz primária (C.R.P) e crescimento do coleóptilo (C.C) de milho

\begin{tabular}{ccccc}
\hline TRATAMENTO & G\% & IVG & C.R.P $(\mathrm{cm})$ & C.C $(\mathrm{cm})$ \\
\hline Etanólico & $1,41 \mathrm{~A}$ & $23,33 \mathrm{~B}$ & $6,83 \mathrm{~A}$ & $2,16 \mathrm{~A}$ \\
Hidroalcoólico 70:30 & $1,37 \mathrm{~B}$ & $23,21 \mathrm{~B}$ & $6,93 \mathrm{~A}$ & $2,19 \mathrm{~A}$ \\
Hidroalcoólico 50:50 & $1,42 \mathrm{~A}$ & $23,90 \mathrm{~A}$ & $6,51 \mathrm{~A}$ & $2,12 \mathrm{~A}$ \\
\hline
\end{tabular}

Médias seguidas da mesma letra, na coluna, não diferem entre si pelo teste de Scott - Knott $(p \leq 0,05)$

Tabela 7 - Efeito das diferentes concentrações de extratos da folha de E. dysenterica sobre a percentagem de germinação (G\%) índice de velocidade de germinação (IVG) crescimento da raiz primária (C.R.P) e crescimento do coleóptilo (C.C) de milho

\begin{tabular}{ccccc}
\hline CONCENTRAÇÃO & G\% & IVG & C.R.P $(\mathrm{cm})$ & C.C $(\mathrm{cm})$ \\
\hline $0 \mathrm{mg} / \mathrm{L}$ & $1,40 \mathrm{~A}$ & $24,00 \mathrm{~A}$ & $7,90 \mathrm{~A}$ & $2,46 \mathrm{~A}$ \\
$250 \mathrm{mg} / \mathrm{L}$ & $1,39 \mathrm{~A}$ & $23,46 \mathrm{~A}$ & $7,19 \mathrm{~A}$ & $2,13 \mathrm{~A}$ \\
$500 \mathrm{mg} / \mathrm{L}$ & $1,38 \mathrm{~A}$ & $23,33 \mathrm{~A}$ & $7,07 \mathrm{~A}$ & $2,24 \mathrm{~A}$ \\
$1000 \mathrm{mg} / \mathrm{L}$ & $1,38 \mathrm{~A}$ & $23,34 \mathrm{~A}$ & $6,90 \mathrm{~A}$ & $2,13 \mathrm{~A}$ \\
$2000 \mathrm{mg} / \mathrm{L}$ & $1,39 \mathrm{~A}$ & $23,09 \mathrm{~A}$ & $5,80 \mathrm{~B}$ & $1,96 \mathrm{~B}$ \\
$4000 \mathrm{mg} / \mathrm{L}$ & $1,35 \mathrm{~A}$ & $22,68 \mathrm{~A}$ & $4,78 \mathrm{C}$ & $1,80 \mathrm{~B}$ \\
\hline
\end{tabular}

Médias seguidas da mesma letra, na coluna, não diferem entre si pelo teste de Scott - Knott $(p \leq 0,05)$

Araújo et al. (2011) também não observaram efeito na porcentagem de germinação e índice de velocidade de germinação de sementes de milho submetidas ao extrato etanólico das folhas de Crotalaria juncea L. (crotalária). Malheiros et al. (2014), por sua vez, utilizando extrato etanólico da folha de Lafoensia pacari A. St. Hill (pacari) verificaram uma inibição média de 35\% no crescimento médio da raiz primária, porém este mesmo extrato não promoveu inibição no coleóptilo. Segundo Aquila et al. (1999) os efeitos alelopáticos de uma mesma planta podem variar de acordo com o órgão onde eles atuam, ou seja, os metabólitos secundários responsáveis por inibirem a radícula/raiz primária podem atuar de maneira diferente no hipocótilo/coleóptilo.

\section{Conclusões}

A alta atividade sequestradora de radicais livres principalmente do extrato etanólico sugere que E. dysenterica é uma fonte natural de substâncias antioxidantes e que pode ajudar no combate às doenças relacionadas ao estresse oxidativo. Em relação à atividade alelopática, os extratos de cagaita inibem o desenvolvimento de alface e milho, observando-se proporcionalidade entre efeito e concentração.

\section{Agradecimentos}

À Fundação de Amparo à Pesquisa do Estado da Bahia (FAPESB), pela concessão de bolsa. 


\section{Referências}

Aquila MEA, Ungaretti JAC, Michelin A. Preliminary observation on allelopathic activity in Achyrocline satureioides (Lam.) DC. Acta Hortic. 1999;(502):383-388.

Araújo SG, Pinto MEA, Silva NL, Santos FJL, Castro AH, Lima LAR. Atividades antioxidante e alelopática do extrato e frações obtidos de Rosmarinus officinalis. Biochem. Biotechnol. Reports. 2013;2(1):35-43.

Araújo EO, Santana CN, Espírito Santo CL. Potencial alelopático de extratos vegetais de Crotalaria juncea sobre a germinação de milho e feijão. Rev. Bras. Agroecologia. 2011;6(1):108-116.

Bezerra JCB, Silva IA, Ferreira HD, Ferri PH, Santos SC. Molluscicidal activity against Biomphalaria glabrata of Brazilian Cerrado medicinal plants. Fitoterapia. 2002;73(5):428-430.

Bara MTF, Couto RO, Valgas AB, Paula JR. Caracterização físico-química do pó das folhas de Eugenia dysenterica DC. (Myrtaceae). Rev. Eletrôn. Farm. 2009;6(3):59-69.

Brasil. Ministério da agricultura e da Reforma Agrária. Regras para a análise de sementes. Brasília, 2009. 357 p.

Falcão HS, Lima IO, Santos VL, Dantas HF, Diniz MFFM, Barbosa-Filho JM, et al. Review of the plants with anti-inflammatory activity studied in Brazil. Rev. Bras. Farmacogn. 2005;15(4):381-391.

Ferreira AG. Interferência, competição e alelopatia. In Ferreira AG, Borghetti F. Germinação: do básico ao aplicado. Porto Alegre: Artmed; 2004. p. 252-264.

Ferreira AG, Aquila MEA. Alelopatia: uma área emergente da ecofisiologia. Rev. Bras. Fisiol. Veg. 2000;(12):175-204.

Frighetto N, Welendorf RM, Silva AMP, Nakamura MJ, Siani AC. Aplicação de cromatografia centrífuga de contra-corrente na purificação de ácido ursólico das folhas de Eugenia brasilensis Lam. Rev. Bras. Farmacogn. 2005;15(4):338-343.
Giotto AC, Oliveira SCC, Silva JPG. Efeito alelopático de Eugenia dysenterica Mart. Ex DC. Berg. (Myrtaceae) na germinação e no crescimento de Lactuca sativa L. (Asteraceae). Rev. Bras. Bioc. 2007;5(2):600-602.

Hüller A, Schock AA. Avaliação do potencial alelopático de três espécies de Eugenia L. (Myrtaceae) sobre o processo germinativo de Lactuca sativa L. Rev. Ciênc. Ambientais. 2011;5(1):25-37.

Labouriau LFG. A germinação das sementes. Departamento de Assuntos Científicos e Tecnológicos da Secretaria Geral da Organização dos Estados Americanos. Washington, 1983. 173 p.

Lapornik B, Prošek M, Wondra AG. Comparison of extract prepared from plant byproducts using different solvents and extraction time. J. Food Engin. 2005;71:(2):214-222.

Lima CP, Cunico MM, Miguel OG, Miguel MD. Efeito dos extratos de duas plantas medicinais do gênero Bidens sobre o crescimento de plântulas de Lactuca sativa L. Rev. Ciênc. Farm. Básica Apl. 2011;32(1):83-87.

Lima NMF, Santos AF, Porfírio Z, Goulart OF, Sant'ana AEG. Toxicity of lapachol and isolapachol and their potassium salt against Biomphalaria glabrata, Schistosoma mansoni, Artemia salina and Tilapia nilotica. Acta Trop. 2002;83(1):43-47.

Linhares Neto MV, Santana FS, Malheiros RSP, Machado LL, Mapeli AM. Avaliação alelopática de extratos etanólicos de Copaifera sabulicola sobre o desenvolvimento inicial de Lactuca sativa, Lycopersicum esculentum e Zea mays. Biotemas. 2014;27(3):23-32.

Magina MDA. Estudo fitoquímico e biológico de espécies do gênero Eugenia [Tese - Doutorado em Química]. Florianópolis: Universidade Federal de Santa Catarina/UFSC; 2008. 178 p.

Maguire JD. Speed of germination-aid in selection and evaluation for seedlig emergence and vigor. Crop Sci. 1962;2(2):176-177. 
Malheiros RSP, Santana FS, Neto MVL, Machado LL, Mapeli AM. Atividade alelopática de extratos de Lafoensia pacari A. ST.-HIL. sobre Lactuca sativa L. e Zea mays L. em condições de laboratório. Rev. Bras. Agroecologia. 2014;9(1):185-194.

Mensor LL, Menezes FS, Leitão GG, Reis AS, Santos TC, Coube CS, et al. Screening of brazilian plant extracts for antioxidant activity by the use of DPPH free radical method. Phytother. Res. 2001;152(2):127-130.

Miranda CASF. Atividade antioxidante de óleos essenciais de folhas de diversas plantas. Dissertação [Mestrado em Agroquímica]. Lavras: Universidade Federal de Lavras/UFLA; 2010. 151 p.

Oliveira RN, Dias IJM, Câmara CAG. Estudo comparativo do óleo essencial de Eugenia punicifolia(HBK) DC. de diferentes localidades de Pernambuco. Rev. Bras. Farmacogn. 2005;15(1):39-43.

Pereira MC, Steffens RS, Jablonski A, Hertz PF, Rios O, Vizzotto $\mathrm{M}$, et al. Characterization and antioxidant potential of brazilian fruits from the Myrtaceae family. J. Agric. Food Chem. 2012;60(12):3061-3067.

Rodrigues VEG, Carvalho DA. Levantamento etnobotânico de plantas medicinais no domínio dos cerrados na região de Alto Rio Grande Minas Gerais. Rev. Bras. Plantas Med. 2007;9(2):17-35.

Romagnolo MB, Souza MC. O gênero Eugenia L. (Myrtaceae) na planície de alagável do Alto Rio Paraná, Estados de Mato Grosso do Sul e Paraná, Brasil. Acta Bot. Bras. 2006;20(3):529-548.

Rosado LDS, Rodrigues HCA, Pinto JEBP, Custódio TN, Pinto LBB, Bertolucci SKV. Alelopatia do extrato aquoso e do óleo essencial de folhas do manjericão "Maria Bonita" na germinação de alface, tomate e melissa. Rev. Bras. Plantas Med. 2009;11(4):422-228.

Salgado PC, Costa MF, Massocatto AM, Junior AL, Frei F, Kolb RM, Santos C. Avaliação do potencial citotóxico, moluscicida e alelopático dos extratos hidroetanólicos das folhas de
Stryphnodendron obovatum Benth. Rev. Bras. Bioc. 2013;11(2):197-202.

Santana DG, Ranal MA, Mustafa PCV, Silva RMG. Germination meansurements to evaluate allelopathic interactions. Allelopathy J. 2006;17(1):43-52.

Silva FSE, Azevedo CAV. Versão do programa computacional Assistat para o sistema operacional Windows. Rev. Bras. Prod. Agroind. 2002;4(1):71-78.

Silva CG, Herdeiro RS, Mathias CJ, Panek AD, Silveira CS, Rodrigues VP, et al. Evalution of antioxidant activity of Brazilian plants. Pharmacol. Res. 2005;52(3):229-233.

Sobral-Souza CE, Leite NF, Cunha FAB, Pinho AI, Costa JGM, Coutinho HDM. Avaliação da atividade antioxidante e citoprotetora dos extratos de Eugenia uniflora Lineau e Psidium sobraleanum Proença \& Landrum contra metais pesados. Rev. Cienc. Salud. 2014;12(3):401-409.

Souza TM, Severi JA, Silva VYA, Santos E, Pietro RCLR. Bioprospecção de atividade antioxidante e antimicrobiana da casca de Stryphnodendron adstringens (Mart.) Coville (Leguminosae-Mimosoidae). Rev. Ciênc. Farm. Básica e Apl. 2007;28(2):221-226.

Souza Filho APS, Rodrigues LRA, Rodrigues TJD. Efeitos do potencial alelopático de três leguminosas forrageiras sobre três invasoras de pastagens. Pesq. Agropec. Bras. 1997;32(2):165170.

Teixeira CM, Araújo JBS, Carvalho GJ. Potencial alelopático de plantas de cobertura no controle de picão-preto (Bidens pilosa L.). Ciênc. Agrotec. 2004;28(3):691-695.

Wandscheer ACD, Pastorini LH. Interferência alelopática de Raphanus raphanistrum L. sobre a germinação de Lactuca sativa L. e Solanum lycopersicon L. Ciênc. Rural. 2008;38(4):949-953. 